\title{
Ultrastructural and biochemical comparison of summer active and summer diapausing pupae of the horse chestnut leaf miner, Cameraria ohridella (Lepidoptera: Gracillariidae)
}

\author{
František WeYdA ${ }^{1}$, JitKa PFLEGEROVÁ ${ }^{2}$, Tereza STAŠKOVÁ ${ }^{2}$, Aleš TOMČAlA ${ }^{3}$, Eva PRENEROVÁ ${ }^{4}$, \\ Rostislav ZEMEK ${ }^{2}$, Lubomír VOLTER ${ }^{5}$ and Dalibor KODRÍK ${ }^{1,2, *}$ \\ ${ }^{1}$ Faculty of Science, University of South Bohemia, Branišovská 31, 37005 České Budějovice, Czech Republic; \\ e-mail:weydafk@seznam.cz \\ ${ }^{2}$ Institute of Entomology, Biology Centre, Academy of Sciences, Branišovská 31, 37005 České Budějovice, Czech Republic; \\ e-mails: kodrik@entu.cas.cz; pfleger@entu.cas.cz; tereza.staskova@gmail.com; rosta@entu.cas.cz \\ ${ }^{3}$ Institute of Organic Chemistry and Biochemistry, Academy of Sciences, Flemingovo sq. 2, 16610 Praha 6, Czech Republic; \\ e-mail: a.tomcala@centrum.cz
}

${ }^{4}$ Laboratory of Plant Protection, Pasovská 1623/16, 37005 České Budějovice, Czech Republic; e-mail: eva.prenerova@seznam.cz

${ }^{5}$ Manětínská 21, 32300 Plzeň, Czech Republic; e-mail: lvolter@post.cz

Key words. Lepidoptera, Gracillariidae, Cameraria ohridella, diapause, pupa, ultrastructure, lipid analysis, nutritional reserves, electron microscopy

\begin{abstract}
The ultrastructural and biochemical characteristics were studied in active and diapausing pupae of the horse chestnut leaf miner, Cameraria ohridella, collected in summer. The active pupae contained developing internal organs, while those in diapause mostly numerous non-differentiated cells packed with stored nutrients. These nutrients occurred in vacuoles as liquid material (lipids, proteins) or as reserve crystaloids (proteins). Triacylglycerols (TGs) were the main lipids stored by pupae and were more abundant in diapausing than active pupae. The amount of diacyglycerols (DGs) and phospholipids (PLs) was almost identical in both groups, which reflects the roles of these compounds in lipid transport and structure of cell membranes, respectively. A principal component analysis (PCA) indicated differences in the quality of the lipid compounds in both groups and that the TGs were mostly responsible for the difference. Polyunsaturated linolenic acid $(18: 3)$ was the most abundant fatty acid in both active and diapausing pupae, nevertheless its content was significantly higher in the former; the level of 7 fatty acids reached values higher than $1 \%$. Differences in other nutrients were similar to those of TGs; higher contents of both glycogen and proteins were recorded in diapausing than active pupae. The results revealed significant differences between the two summer pupal forms of $C$. ohridella and furthered our understanding of the developmental strategy of this successful, invasive pest insect.
\end{abstract}

\section{INTRODUCTION}

The horse chestnut leaf miner, Cameraria ohridella, belongs to the lepidopteran family Gracillariidae. It feeds on horse chestnut, Aesculus hyppocastanum, where it lives inside leaves and feeds on their internal tissues; in temperate Europe it produces 3 or 4 generations per year (Skuhravý, 1998). Despite C. ohridella currently being one of the most important insect pest species of ornamental trees in Europe (Zemek et al., 2007a, b) the details of its bionomy and biology are poorly known.

The adults of $C$. ohridella are small brown moths with a white markings on their wings; they are about $4 \mathrm{~mm}$ long with a $7 \mathrm{~mm}$ wing span. The females lay eggs on the surface of leaves and after hatching the larvae burrow into to the assimilatory parenchyma of a leaf where they suck liquid from the cells and create typical cavities called mines (Weyda \& Hrdý, 2002). The liquid excrements they deposit in the mines result in distinct circular spots about $1 \mathrm{~cm}$ in diameter. Photosynthesis of attacked leaves is reduced, which leads to a nutritional disturbance of the whole tree, defoliation, smaller seeds (Percival et al., 2011) and general weakening. At the end of their development the larvae of $C$. ohridella create pupal chambers (Skuhravý, 1998), each of which is enclosed in a solid parchment silk cocoon, which probably protects the insect against environmental changes, natural enemies and pathogens.

An interesting aspect of the development of $C$. ohridella is the occurrence of two types of pupae (Skuhravý, 1998; Samek, 2003; Hněvsová et al., 2011): (1) Active (non diapausing) pupae - typical of the generations that develop within the vegetative season. They are produced by the last instar larvae, which spin soft incomplete cocoons that consist of just a thin layer of silk containing substantially less material than the cocoons of the following group. These active pupae are not able to overwinter. (2) Diapausing pupae - their percentage is low in the first generation of the year, however, the percentage increases in the following generations (Samek, 2003). The larvae predestined to develop into diapausing pupae produce hard, complete cocoons that fully line the pupal chamber (Hněvsová et al., 2011). Only diapausing pupae are able to overwinter. The adults that emerge from these pupae eclose the following spring, the females lay eggs after mating and the developmental cycle starts again.

The phenomenon as to why diapausing pupae are formed in all generations within a year is not fully understood in terms of how it is controlled and the developmental or evolutional background is also unclear. Thus, the main aim of the present study was to

\footnotetext{
* Corresponding author.
} 
describe certain morphological and biochemical differences between active and diapausing pupae and increase our understanding of the developmental strategy of $C$. ohridella.

\section{MATERIAL AND METHODS}

\section{Cameraria ohridella pupae}

Fresh horse chestnut leaves containing $C$. ohridella pupae were collected in the vicinity of České Budějovice (Czech Republic, $49^{\circ} \mathrm{N}$ ) from $7^{\text {th }}$ to $17^{\text {th }}$ July 2012 . The pupae were immediately dissected from the leaves and cocoons under a dissecting microscope and then checked to determine whether they were alive by stimulating them mechanically; dead pupae were discarded. Based on the type of cocoon and overall appearance (see below), the pupae were as either active or diapausing. Those used for the ultrastructural studies were processed immediately, while those used for the biochemical analyses were stored at $-24^{\circ} \mathrm{C}$ until required. The diapausing pupae were homogenous, while the active pupae were more variable; individuals with pharate adult features were excluded from morphological studies, nevertheless, contamination of those used for biochemical analyses with these individuals cannot be excluded. However, this would have affected only the variability of the results, not their reliability.

\section{Size of pupae}

For measuring the size of the pupae a conventional flatbed scanner (Canon 8800F) was used; Petri dishes with pupae were inserted inside the scanner and scanned using direct optical (not interpolated) resolution (1200 dpi). The primary pictures were sharp enough to be suitable for the measuring their length. The length was measured on the pictures obtained using ruler-like software, which counts the number of pixels (Weyda, 2006).

\section{Light and electron microscopy}

For morphological and ultrastructural studies, optical and conventional transmission electron microscopy (TEM) were used. For this the freshly collected pupae were fixed in a mixture of $2 \%$ glutaraldehyde and $2.5 \%$ formaldehyde (EM grade) in $0.1 \mathrm{M}$ phosphate buffer, postfixed in $1 \%$ osmium tetroxide, dehydrated in a series of ethanols, embedded in epoxy resin (Spurr or mixture epon-araldite) and polymerized at $60^{\circ} \mathrm{C}$. For optical microscopy semithin plastic sections $(1 \mu \mathrm{m})$ were cut and stained with toluidine blue. For the TEM ultrathin sections were cut on Leitz ultramicrotome, stained with uranyl acetate-lead citrate and observed in Jeol 1010 transmission electron microscope.

\section{Determination of lipids}

Lipids were extracted from $C$. ohridella pupae using a chloroform: methanol $(2: 1)$ solution following the method of Folch et al. (1957) as modified by Košt’ál \& Šimek (1998). Each pupa was homogenized in the solution and appropriate aliquots were used for the lipid determination. The procedure employed an ion trap LTQ mass spectrometer coupled to an Allegro ternary HPLC system equipped with an Accela autosampler with a thermostat chamber (all by Thermo, San Jose, CA, USA). The samples ( 5 $\mu$ l) were separated using a Gemini column $250 \times 2 \mathrm{~mm}$ i.d. $3 \mu \mathrm{m}$ (Phenomenex, Torrance, CA, USA). The mobile phase consisted of (A) $5 \mathrm{mM}$ ammonium acetate in methanol, (B) water and (C) 2-propanol. The analysis was completed within 80 minutes using a flow rate of $200 \mu \mathrm{l} / \mathrm{min}$ and the following gradient: $0-5 \mathrm{~min}$ $92 \% \mathrm{~A}$ and $8 \% \mathrm{~B}, 5-12 \mathrm{~min} 100 \% \mathrm{~A}, 12-50 \mathrm{~min} 100-40 \% \mathrm{~A}$ and $0-60 \% \mathrm{C}, 50-65 \mathrm{~min} 40 \% \mathrm{~A}$ and $60 \% \mathrm{C}$, and $65-80 \mathrm{~min}$ back to the $92 \% \mathrm{~A}$ and $8 \% \mathrm{~B}$. The column temperature was maintained at $30^{\circ} \mathrm{C}$. The mass spectrometer was operated in the positive and negative ion detection modes at $+4 \mathrm{kV}$ and $-4 \mathrm{kV}$ with a capillary temperature of $220^{\circ} \mathrm{C}$. The nitrogen was employed as a shield and

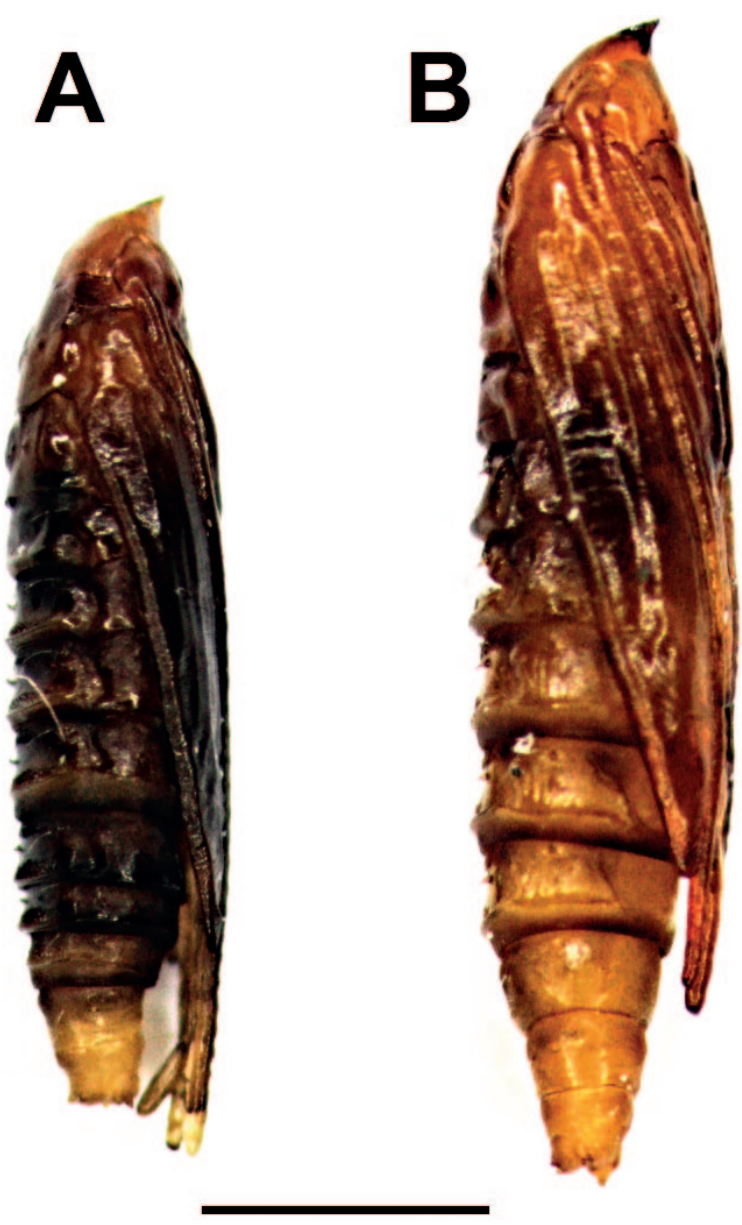

Fig. 1. The external appearance of the two types of pupae of C. ohridella. A - active pupa, B - diapausing pupa. Bar $=1 \mathrm{~mm}$.

auxiliary gas for both polarities. Mass range of 140-1400 Da was scanned every $0.5 \mathrm{~s}$ to obtain the full scan ESI mass spectra of lipids. For the investigation of the structures of the lipid molecules, the collisionally induced decomposition multi-stage ion trap tandem mass spectra $\mathrm{MS}^{2}$ in both polarity settings were simultaneously recorded with a $3 \mathrm{Da}$ isolation window. Maximum ion injection time was $100 \mathrm{~ms}$ and normalized collision energy $35 \%$. The structure of each entity was identified using $\mathrm{MS}^{2}$ experiments in positive or negative mode. Peak areas of detected lipids were used for estimating their relative content in the samples.

\section{Determination of proteins}

The proteins from the $C$. ohridella pupae were isolated using $0.2 \mathrm{M}$ Tris- $\mathrm{HCl}$ buffer, $\mathrm{pH} 7.8$, containing $1 \%$ triton. Each pupa was homogenized in this solution and the protein content measured in an appropriate aliquot using bicinchoninic acid reagent (Stoscheck, 1990). The bovine serum albumin standard curve was used to convert the optical densities of the samples measured at $562 \mathrm{~nm}$ into $\mu \mathrm{g}$ of protein.

\section{Determination of glycogen}

The glycogen content in the $C$. ohridella pupae was measured using the procedure of Ohtsu et al. (1992). The concentration of glucose liberated by the hydrolysis of glycogen was estimated using a modified anthrone method according to Carol et al. (1956) where the sample absorbance was read at $620 \mathrm{~nm}$. A glucose standard curve was used to determine the quantity of glycogen. 


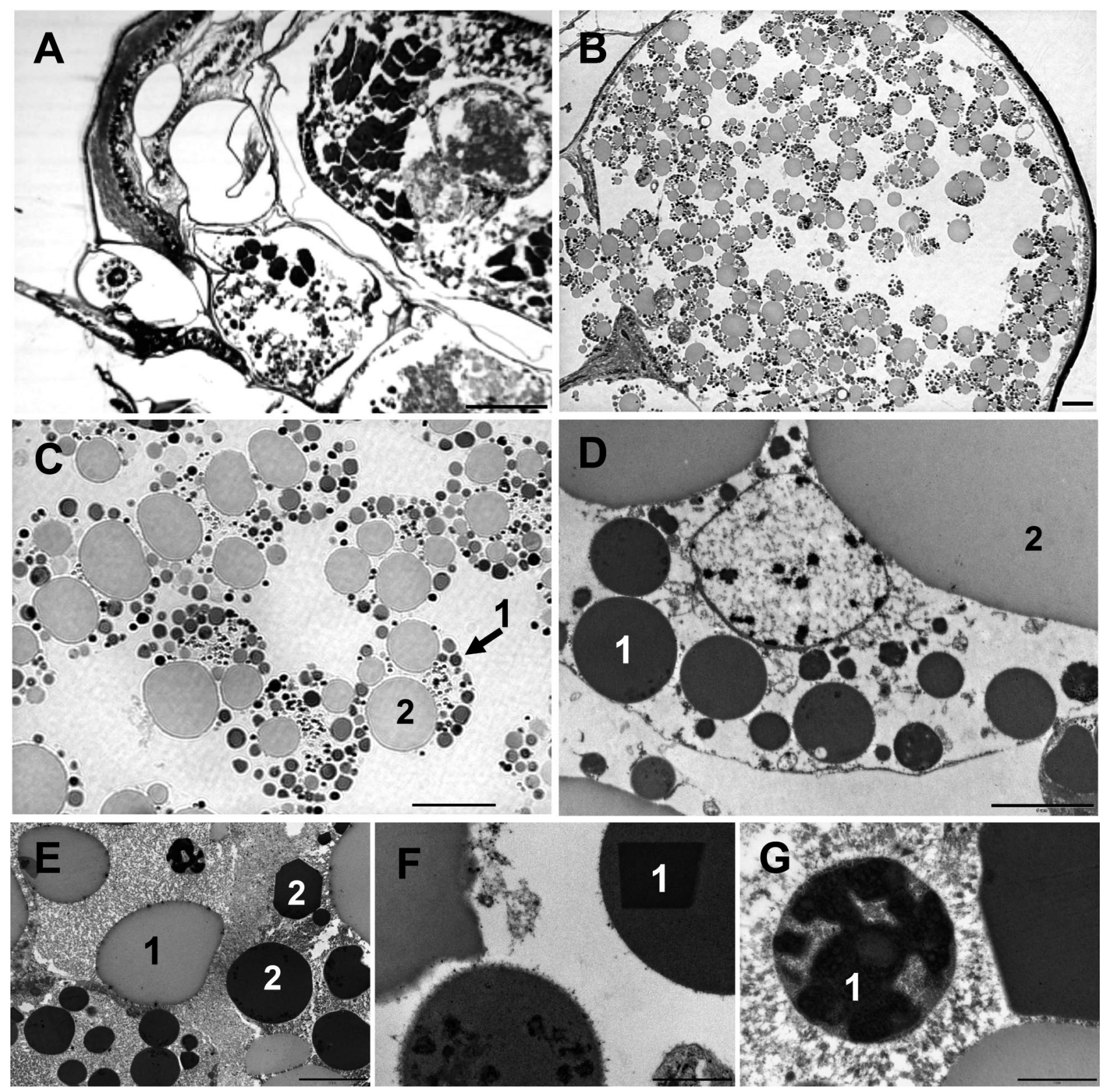

Fig. 2. Cross sections through pupae of $C$. ohridella showing the ultrastucture of storage cells. A, B, C-sections viewed using optical microscopy; D, E, F, G - sections viewed using transmission electron microscope (TEM). A - cross section of the body of an active pupa containing developing organs (half way through the development of an active pupa), bar $=100 \mu \mathrm{m}$; B - cross section of the body of a diapausing pupa containing storage cells (grey circles), bar $=100 \mu \mathrm{m} ; \mathrm{C}$ - storage cells of a diapausing pupa containing vacuoles, bar $=20 \mu \mathrm{m}, 1$ - protein vacuole; 2 - lipid vacuole; D - details of a storage cell of a diapausing pupa, bar $=5 \mu \mathrm{m}, 1-$ protein vacuole; 2 - lipid vacuole; there is a nucleus cut tangentially in the centre of the photograph; E - ultrastructure of storage cells of a diapausing pupa, bar $=5 \mu \mathrm{m}, 1-$ lipid vacuole, $2-$ several types of protein vacuoles; $\mathrm{F}-$ ultrastructure of storage cells of a diapausing pupa, bar = $2 \mu \mathrm{m}, 1$ - protein vacuole; $\mathrm{G}$ - heterogeneous protein vacuole (1) in a storage cell of a diapausing pupa, bar $=2 \mu \mathrm{m}$.

\section{Data presentation and statistical analyses}

The biochemical results were plotted using the graphic program Prism (GraphPad Software, version 6.01, San Diego, CA, USA). The bar graphs, Figs $3(n=5)$ and $5(n=6-11)$, present means \pm SDs. For statistical evaluation of the results in Figs 3 and 5 , and Table 1 see the corresponding legends.

Data obtained from the lipidomic HPLC/ESI/MS determination (active and diapausing pupae) were analyzed using Principal Component Analysis (PCA). For this analysis, the peak areas of compounds detected in total lipid extracts of $C$. ohridella pupae were used. Prior to the PCA analysis, the peak areas of 260 lipidic compounds were subjected to logarithmic transformation, scaling was focused on inter-species correlation, and the species scores were divided by their standard deviations and the data centred by species. In the PCA analyses, samples with similar chemical profiles were clustered together and segregated from those that were different. The statistical significance was assessed using redundancy analysis (RDA), a canonical variant of PCA, and the Monte Carlo permutation test (unrestricted permutations, $n=999$ ); the identities of the tested groups (active and diapausing pupae) 

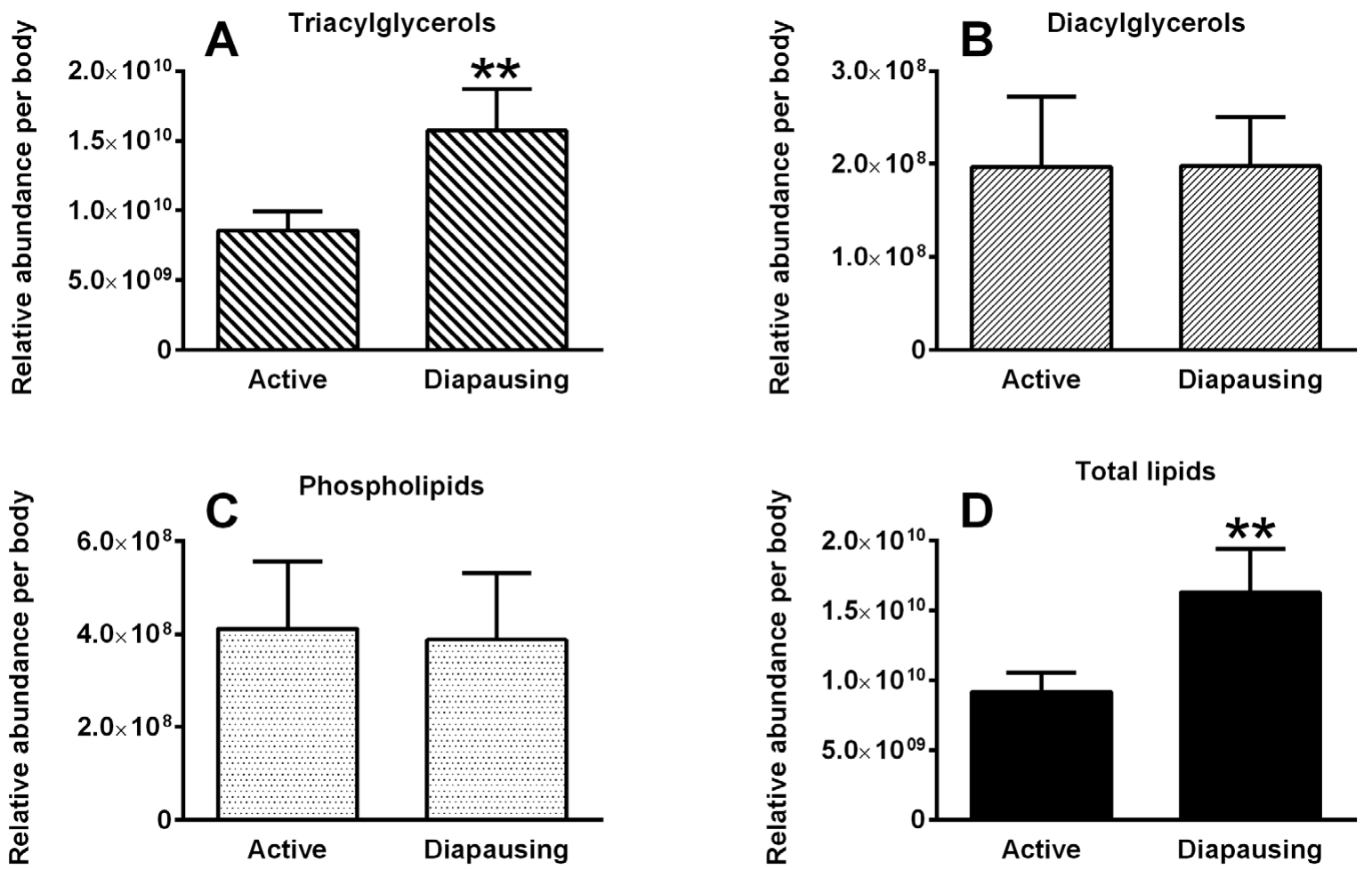

Fig. 3. Relative abundances of triacylglycerols (A), diacylglycerols (B), phospholipids (C) and total lipids (D) in the bodies of active and diapausing pupae of $C$. ohridella. Asterisks indicate significant differences between the active and diapausing pupae at $\mathrm{P}<0.01$ evaluated using Student's t-test; $\mathrm{n}_{1}=\mathrm{n}_{2}=5$.

were used as a categorical predictor in the RDA analysis. This analysis also determined compounds responsible for the sample segregation. The multivariate data analysis software CANOCO 4.5 (Biometris, Plant Research International, Wageningen UR, The Netherlands) was used for both the PCA and RDA analyses.

\section{RESULTS}

\section{Structural and ultrastructural characterization}

This study revealed that the active and diapausing pupae of $C$. ohridella that appear simultaneously in summer differ in colour and size: the diapausing pupae were yellowish while the active pupae were brown (Fig. 1). In addition, the active pupae (3.46 $\pm 0.06 \mathrm{~mm}, \mathrm{n}=25$ ) were significantly smaller (unpaired t-test, $\mathrm{p}<0.01)$ than diapausing pupae $(3.81 \pm 0.02 \mathrm{~mm}, \mathrm{n}=25)$. In accordance with their size the active pupae $(1.50 \pm 0.28 \mathrm{mg}, \mathrm{n}=10)$ were significantly lighter (unpaired t-test, $\mathrm{p}<0.01$ ) than diapausing pupae $(1.93 \pm 0.18 \mathrm{mg}, \mathrm{n}=10)$.

In addition, substantial differences in organ and subcellular anatomy between both types of pupae were found using optical (histological semithin plastic sections of $1 \mu \mathrm{m}$ thickness) and/or transmission electron microscopy. While active pupae contained developing internal organs (Fig. 2A) only numerous non-differentiated "storage" cells (Fig. 2B) were present in diapausing pupae. Nevertheless, these storage cells were rarely found in active pupae (data not shown). Typical storage cells were characterized by a circular shape and the presence of many vacuoles (Fig. 2C, D). Lighter and much bigger lipid vacuoles (their diameter was often more than $20 \mu \mathrm{m}$ ) were homogeneous, while darker protein vacuoles, mostly heterogenous, were much smaller with a diameter of 2-6 $\mu \mathrm{m}$ (Fig. 2C, D). Some of the vacuoles contained irregularly shaped condensed material and regularly shaped reserve crystaloids (Fig. 2E, F, G).

\section{Nutritional reserves}

The HPLC/MS analyses of the lipids extracted from C. ohridella pupae using chloroform-methanol generated a number of MS peaks, which indicated about 260 lipidic compounds (data not shown). For practical reasons, they were clustered into TGs, DGs and PLs (see also Material and Methods section). Their quantification revealed a significant difference between active and diapausing pupae in terms of TGs (Fig. $3 \mathrm{~A}, \mathrm{P}=0.0031$ ). Their level in diapausing pupae was about 1.8 higher than in active pupae. The lipids destined for direct utilization are ordinarily transported to the target tissues as DGs in insects; in accordance with this the DG content was similar in both types of pupae (Fig. 3B, P = 0.9796). A similar picture is shown in Fig. 3C, in which the level of PLs is depicted: no difference between the active and diapausing pupae was recorded $(\mathrm{P}=0.8285)$. The significant difference in total lipids (data for TGs, DGs and PLs together - Fig. 3D, $\mathrm{P}=0.0038$ ) is not surprising as it reflects the difference in TGs and the levels of DGs and PLs were about 1-2 orders of magnitude less than that of TGs (Fig. 3), thus, their effect on the total lipid level was negligible. These findings were further confirmed by the PCA (Fig. 4). This statistical test indicated differences in the quality of particular lipidic compounds in the two groups and that TGs are mostly responsible for the difference. A RDA analysis confirmed the statistical significance of the difference at the $\mathrm{p}=0.018$ level (data not shown).

The above raises the question - Are the differences in the lipids in the two types of pupae also apparent at the level of fatty acids (FAs)? Indeed, the analysis indicated a significant selectivity in the accumulation and/or utilization of certain FAs by active and diapausing pupae (Table 1). Linolenic acid (18:3) was unequivocally the most abundant FA representing almost one half of all identified FAs. In addition, the following three FAs oleic (18:1), linoleic $(18: 2)$ and palmitic $(16: 0)$, reached levels between $11-14 \%$, respectively. The levels of another three FAs 


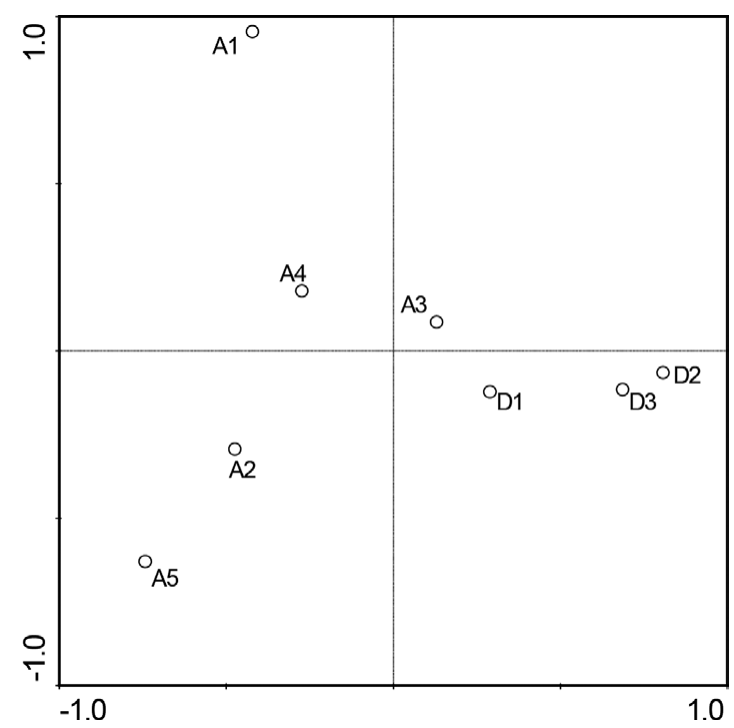

Fig. 4. The PCA evaluation of differences in lipid composition of active (A) and diapausing (D) pupae of C. ohridella. Subsequent RDA and Monte Carlo test (data not shown) indicated significance differences between these two types of pupae (A vs. D) at $\mathrm{P}=0.018$ level.

studied, stearic (18:0), palmitoleic (16:1) and margaric (17:0), were less than $10 \%$, respectively; the FAs with levels of less than $1 \%$ were not considered. Further, there were significantly higher levels of palmitoleic $(16: 1)$ and linoleic $(18: 2)$ acids, and a lower level of linolenic $(18: 3)$ acid in diapausing than active pupae. The relatively lower level of linolenic acids $(18: 3)$ indicates that the role of these FAs might be more than only a source of energy during diapause.

Results of the analyses of the other nutrients in the two types of pupae studied were similar to those obtained for total lipid content, with 1.3 times more protein and 1.5 times more glycogen recorded in diapausing than active pupae (Fig. 5).

\section{DISCUSSION}

Within the last decade $C$. ohridella has gradually became a serious pest of horse chestnut trees in Europe, which has increased the interest in this small moth and revealed new facts about various aspects of its biology (Zemek et al., 2012; D'Costa et al.,

TABLE 1. Summary of the percentage (mean $\pm \mathrm{SD}$ ) of the most abundant fatty acids (FA) (reaching at least 1\% content; their total content $>96 \%$ ) in the total lipids (TGs, DGs, and PLs) in $C$. ohridella pupae. Statistically significant differences between the active (A) and diapausing (D) pupae for each FA were evaluated using Student's t-test. The arcsine square-root transformation (Sokal \& Rohlf, 1969) was applied to normalize the percentage data before the statistical analysis. Significant differences $(P<$ 0.05 ) are shown in bold.

\begin{tabular}{cccccccc}
\hline \multirow{2}{*}{ Fatty acid } & \multicolumn{2}{c}{ Pupae } & & \multicolumn{3}{c}{ Statistics } \\
\cline { 2 - 3 } \cline { 5 - 6 } & Active & Diapausing & & $t$ & $\mathrm{df}$ & $P$ \\
\hline $16: 0$ & $12.89 \pm 1.21$ & $12.25 \pm 1.03$ & & 0.7461 & 6 & 0.4838 \\
$16: 1$ & $\mathbf{3 . 5 6} \pm \mathbf{1 . 0 8}$ & $\mathbf{5 . 4 0} \pm \mathbf{0 . 8 1}$ & & 2.5847 & 6 & 0.0415 \\
$17: 0$ & $0.96 \pm 0.10$ & $0.83 \pm 0.10$ & & 1.6743 & 6 & 0.1451 \\
$18: 0$ & $8.40 \pm 2.27$ & $8.35 \pm 1.78$ & & 0.0101 & 6 & 0.9922 \\
$18: 1$ & $11.66 \pm 2.48$ & $14.54 \pm 1.87$ & & 1.7053 & 6 & 0.1390 \\
$18: 2$ & $\mathbf{1 1 . 6 0} \pm \mathbf{0 . 8 8}$ & $\mathbf{1 3 . 5 9} \pm \mathbf{1 . 1 0}$ & & 2.8192 & 6 & 0.0304 \\
$18: 3$ & $\mathbf{4 7 . 4 6} \pm \mathbf{3 . 4 5}$ & $\mathbf{4 1 . 3 4} \pm \mathbf{1 . 7 9}$ & & 2.7984 & 6 & 0.0312 \\
\hline
\end{tabular}
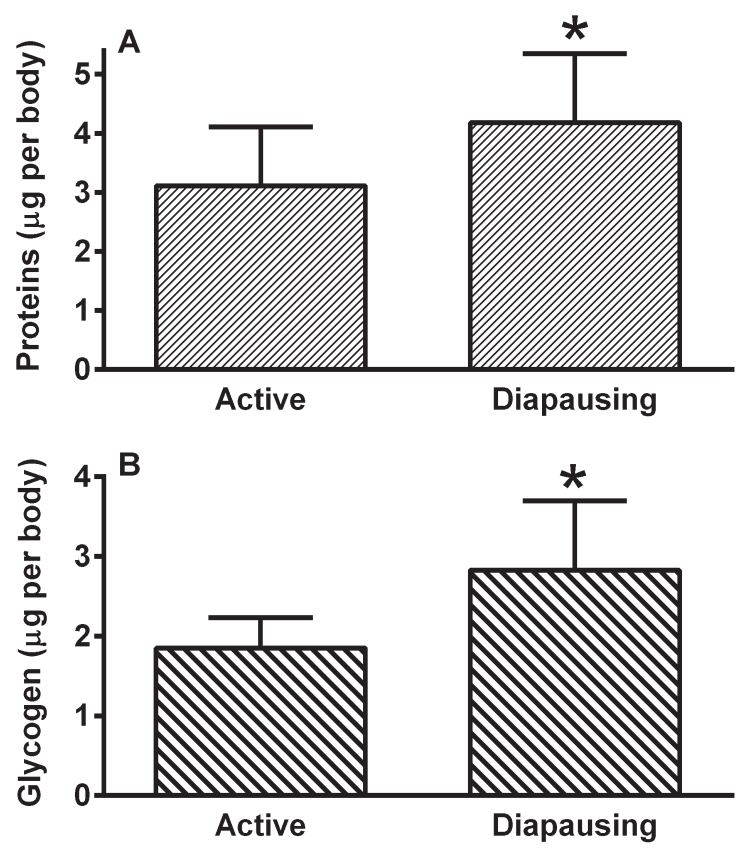

Fig. 5. Protein (A) and glycogen (B) levels recorded in the bodies of active and diapausing pupae of $C$. ohridella. Statistically significant differences at the $5 \%$ level between active and diapausing pupae evaluated using Student's t-test are indicated by an asterisk; $\mathrm{n}=6-11$.

2013; Irzykowska et al., 2013; Straw \& Williams, 2013; Pocock \& Evans, 2014). An interesting and important aspect of the life history strategy of $C$. ohridella is that it produces two different types of pupae throughout the vegetative period, active and diapausing (Skuhravý, 1998). It is surprising that the adaptive value of the parallel co-existence of diapausing and active pupae in summer is still unknown. Nevertheless, various interruptions in development (quiescence, diapause) in summer are well-known and well described in insects (Koštál, 2006). The summer diapause is a common phenomenon in insects: it occurs in all developmental stages and was recorded in all climatic regions. For example, within the Lepidoptera summer diapause is recorded in about 80 species, mostly occurring in pupal or adult stages (Masaki, 1980). There are several reasons for summer diapause, high temperature, drought, low food availability, predation pressure, synchronization and stabilization of development, nevertheless none of these account for diapausing and active pupae being produced at the same time by $C$. ohridella.

Thus, it is apparent that a certain percentage of pupae in each generation of $C$. ohridella enter diapause although the environmental conditions are optimal for active life (Šefrová \& Laštůvka, 2001). Only a small percentage (5-13\%) enter diapause in the first spring generation (usually May), however, the percentage increases gradually in the following generations. In the second generation it reaches $20-35 \%$ and finally in the third and fourth generations, (usually in September or October, depending on the weather) most pupae diapause (Skuhravý, pers. commun., 2007). The percentage of pupae entering diapause is variable in each generation, which might be correlated with the availability of food as mentioned by Samek (2003), who also records that the percentage of pupae in diapause in the first generation is highly correlated with the population of this pest or the extent of leaf damage. Freise \& Heitland (2002) even suggest that some pupae remain in diapause at least for three years.

The present study revealed that active and diapausing pupae also differed in their anatomy. The body cavity of both types of 
pupae contained approximately circular storage cells. They were very abundant in diapausing pupae and contained various nutrients mostly in vacuoles in the cells. It is believed that these nutrients support diapausing pupae during the whole non-feeding period, including overwintering. On the other hand, storage cells were rarely seen in active pupae and then mostly surrounding the rudiments of developing organs. It is probable that the nutrients are quickly utilized by actively developing pupae and that they provide the energy and structural components for metamorphosis, which ends about 10 days after pupation (Samek, 2003).

In addition, the active and diapausing pupae of $C$. ohridella differ also in the amount and quality of the silk in their cocoons (Hněvsová et al., 2011). The cocoons vary not only in macroscopic appearance and size, but in the quality of the silk. The major component of lepidopteran silk is fibroin, which is coated with several sericin proteins. This type of structure is typically associated with several small proteins with various functions. One, or several of the proteins work as protease inhibitors, which protect the cocoons against microbes (Nirmala et al., 2001a, b; Žurovec et al., 1998). Hněvsová et al. (2011) report that the inhibition of protease activity by an extract of the silk from active pupae is greater than by an extract of silk from diapausing pupae of $C$. ohridella. These authors suggest that the higher inhibitory activity in the silk of active pupae might reflect the necessity for a stronger protection of cocoon against microbes (and predatory insects) during the vegetative period than overwinter. In addition, pupae of $C$. ohridella have other sophisticated defence systems (Fiolka et al., 2005).

Successful overwintering requires the accumulation of a sufficient amount of energy rich nutrients within the vegetative season in order to survive the following non-feeding period. Accordingly, the total lipid level in diapausing pupae was significantly greater than in active pupae. Triacylglycerols (TGs), which are an important reserve of energy in insects [in diapausing insects they make up as much as $80-95 \%$ of total lipid content (Hahn \& Denlinger, 2011)], were also the dominant lipids in $C$. ohridella. The contents of the other classes of lipids were much lower (see Fig. 3). It is not surprising that the level of diacylglycerols (DGs) was almost identical in active and diapausing pupae. The DGs serve mainly as transport lipids in insects (Van der Horst, 1982; Arrese et al., 1996) and their level is more or less independent of the total lipid level. A similar situation was recorded for phospholipids (PLs). This interesting class of lipids is an important structural component of cell membranes and affects their characteristics, which is important for the survival of insects at low temperatures. Both of the types of pupae studied were collected in the field at the same time of year and had both experienced identical temperature conditions, which probably accounts for the same level of PLs in both active and diapausing pupae. Whether the level of PLs in diapausing pupae of $C$. ohridella changes during autumn and winter, when exterior temperature can be very low, is unknown and remains to be elucidated.

Fatty acids (FAs) are the main components of lipids. Several dozen FAs are described in insects, however, 8-9 FAs with 12-18 carbon atoms in the molecule make up the major proportion. The saturated FAs are lauric $(12: 0)$, myristic $(14: 0)$, palmitic $(16: 0)$ and stearic $(18: 0)$, the monounsaturated FAs myristoleic $(14: 1)$, palmitoleic $(16: 1)$ and oleic $(18: 1)$ and polyunsaturated FAs linoleic (18:2) and linolenic (18:3) (Downer, 1985; Schneider $\&$ Dorn, 1994). The most common FAs in C. ohridella are included in these categories (see Table 1). Linolenic acid seems to be the most abundant in both pupal groups and is significantly more abundant in active than diapausing pupae, which indicates it is not only a source of energy. A high level of linolenic acid is also recorded in the locust, Locusta migratoria (Tomčala et al., 2010) and firebug, Pyrrhocoris apterus (Bártů et al., 2010). Oleic and linoleic acids, however, are the most abundant FAs in the latter two species, respectively. Level of the next two FAs in C. ohridella, palmitoleic and linoleic, is slightly, but significantly higher in diapausing pupae, which might indicate they are more important energy reserves for the long non-feeding period.

The determination of the levels of the other nutrients in $C$. ohridella, glycogen and proteins, did not result in any surprizes. As in the case of lipids their level was higher in diapausing pupae. Fat body glycogen generally has two main roles in insect diapause: (1) an energy reserve supplementing the role of TGs, and (2) a source of various cryoprotectants (Hahn \& Denlinger, 2011). Whether the latter role is important for pupae of C. ohridella is unknown. Diapausing insects also accumulate proteins (mostly in the form of hexamerins), which probably have a role in anabolic activities and turnover of amino acids, some of which may play a role in nutrient storage (Hahn \& Denlinger, 2011). Again, the details of the role of proteins in diapausing pupae of $C$. ohridella are unknown.

The morphometric evaluation of the pupae revealed that the diapausing pupae were significantly larger and heavier than non diapausing pupae. It is likely that the maximum levels of nutrients (lipids, glycogen, proteins) in pupae are limited and diapausing pupae are not able to increase their concentrations substantially (data not shown). To overcome this limitation diapausing pupae are larger and heavier and so accumulate more nutrients for a much longer non-feeding period than experienced by active pupae.

In summary, this paper deals with structural and biochemical characteristics of $C$. ohridella pupae. This study revealed significant differences in anatomy, cell structure and ultrastructure, and in the quantity and quality of nutrients in the active and diapausing pupae that develop in summer. However, the adaptive significance of producing two types of pupae in summer is unknown. It apparently represents one of evolutionary adaptations making this species so successful.

ACKNOWLEDGEMENTS. This study was supported by the Institute of Entomology project RVO 60077344, and University of South Bohemia grant GAJU 038/2014/P. The authors thank H. Štěrbová and J. Jabůrková for their technical assistance, and Jessica and Jakub Avramov (TN, USA) for their correction of English.

\section{REFERENCES}

Arrese E.L., Rojas-Rivas B.I. \& Wells M.A. 1996: The use of decapitated insects to study lipid mobilization in adult Manduca sexta, effects of adipokinetic hormone and trehalose on fat body lipase activity. - Insect Biochem. Mol. Biol. 26: 775-782.

Bártư I., TomČala A., Socha R., Šimek P. \& Kodrík D. 2010: Analysis of lipids mobilized by adipokinetic hormones in the firebug Pyrrhocoris apterus (Heteroptera: Pyrrhocoridae). Eur. J. Entomol. 107: 509-520.

Carol N.V., Longley R.W. \& Roe J.H. 1956: The determination of glycogen in liver and muscles by use of anthron reagent. J. Biol. Chem. 220: 583-586.

D'Costa L., Koricheva J., Straw N. \& Simmonds M.S.J. 2013: Oviposition patterns and larval damage by the invasive horsechestnut leaf miner Cameraria ohridella on different species of Aesculus. - Ecol. Entomol. 38: 456-462.

DOWNER R.G.H. 1985: Lipid metabolism. In Kerkut G.A. \& Gilbert L.I. (eds): Comprehensive Insect Physiology, Biochemistry and Pharmacology. Vol. 10. Pergamon Press, Oxford, pp $77-113$ 
FioŁka M.J., Ptaszyńska A.A. \& Czarniawski W. 2005: Antibacterial and antifungal lysozyme-type activity in Cameraria ohridella pupae. - J. Invertebr. Pathol. 90: 1-9.

Folch J., Lees M. \& Sloane Stanley G.H. 1957: A simple method for the isolation and purification of total lipids from animal tissues. - J. Biol. Chem. 226: 497-509.

Freise J. \& Heitland V. 2002: Diapausing behaviour of $\mathrm{Ca}$ meraria ohridella (Deschka et Dimic) (Lep., Gracillariidae) and its influence on the moth's population dynamics. Congress Abstracts from VIIth European Congress of Entomology, Greece, Thessaloniki. Hellenic Entomological Society, Thessaloniki, p. 271.

Hahn D.A. \& Denlinger D.L. 2011: Energetics of insect diapause. - Annu. Rev. Entomol. 56: 103-121.

HNĚvsová V., Kodrík D. \& Weyda F. 2011: Contribution to the biochemical characterization of the silk and structure characterization of the cocoons of the horse chestnut leaf miner Cameraria ohridella (Lepidoptera: Gracillariidae). — Eur. J. Entomol. 108: 711-715.

Irzykowska L., Werner M., Bocianowski J., Karolewski Z. \& FRUZYNSKA-JOZWIAK D. 2013: Genetic variation of horse chestnut and red horse chestnut and trees susceptibility to Erysiphe flexuosa and Cameraria ohridella. - Biologia 68: 851-860.

KošŤÁL V. 2006: Eco-physiological phases of insect diapause. J. Insect Physiol. 52: 113-127.

KošŤÁL V. \& ŠIMEK P. 1998: Changes in fatty acid composition of phospholipids and triacylglycerols after cold-acclimation of an aestivating insect prepupa. - J. Comp. Physiol. (B) 168 453-460.

Masaki S. 1980: Summer diapause. - Annu. Rev. Entomol. 25 $1-25$.

Nirmala X., Kodrík D., Žurovec M. \& Sehnal F. 2001a: Insect silk contains both a Kunitz-type and a unique Kazal-type proteinase inhibitors. - Eur. J. Biochem. 268: 2064-2073.

Nirmala X., Mita K., Vanisree V., Žurovec M. \& Sehnal F. 2001b: Identification of four small molecular mass proteins in the silk of Bombyx mori. — Insect Mol. Biol. 10: 437-445.

OHTSu T., KimUra M.T. \& Hori S.H. 1992: Energy storage during reproductive diapause in the Drosophila melanogaster species group. - J. Comp. Physiol. (B) 162: 203-208.

Percival G.C., Barrow I., Novissa K., Keary I. \& Pennington P. 2011: The impact of horse chestnut leaf miner (Cameraria ohridella Deschka and Dimić; HCLM) on vitality, growth and reproduction of Aesculus hippocastanum L. - Urban Forest. Urban Green. 10: 11-17.

Pocock M.J.O. \& Evans D.M. 2014: The success of the horsechestnut leaf-miner, Cameraria ohridella, in the UK revealed with hypothesis-led citizen science. — PLOS ONE 9(1): e86226. doi:10.1371/journal.pone. 0086226

SAMEK T. 2003: Diapause of Cameraria ohridella Deschka et Dimic and its impact on the species population dynamics. - J. Forest. Sci. 49: 252-258.
SCHNEIDER M. \& Dorn A. 1994: Lipid storage and mobilization by flight in relation to phase and age of Schistocerca gregaria females. - Insect Biochem. Mol. Biol. 24: 883-889.

ŠEFrovÁ H. \& LAŠTƯVKa Z. 2001: Dispersal of the horse-chestnut leafminer, Cameraria ohridella Deschka \& Dimic, 1986, in Europe: its course, ways and causes (Lepidoptera: Gracillariidae). - Entomol. Z. 111: 194-197.

SkuHRAVÝ V. 1998: Zur Kenntnis der Blattminen - Motte Cameraria ohridella Deschka \& Dimic (Lepidoptera, Lithocolletidae) an Aesculus hippocastanum L. in der Tschechischen Republik. — Anz. Schädlingskunde / J. Pest Sci. 71: 82-84.

Sokal R.R. \& Rohlf F.J. 1969: Biometry. Freeman, San Francisco, $937 \mathrm{pp}$.

Stoscheск C.M. 1990: Quantitation of proteins. - Methods Enzymol. 182: 50-68.

StraW N.A. \& Williams D.T. 2013: Impact of the leaf miner Cameraria ohridella (Lepidoptera: Gracillariidae) and bleeding canker disease on horse-chestnut: direct effects and interaction. - Agric. Forest Entomol. 15: 321-333.

TomČAla A., BÁrtů I., ŠimeK P. \& Kodrík D. 2010: Locust adipokinetic hormone mobilizes diacylglycerols selectively. Comp. Biochem. Physiol. (B) 156: 26-32.

VAN DER HORST D.J. 1982: Lipid transport in insects. In Mittler T.E. \& Dadd R.H. (eds): Metabolic Aspects of Lipid Nutrition in Insects. Westview Press, Boulder, pp. 183-202.

WeYDA F. 2006: Digital imaging of the horse chestnut leafminer, Cameraria ohridella (Lepidoptera, Gracillariidae). In: Proceedings of the XVII. Czech and Slovak Plant Protection Conference. Prague, pp. 541-544.

WEYDA F. \& HRDÝ I. 2002: Imaging of horse chestnut leafminer, Cameraria ohridella (Lepidoptera, Gracillariidae, Lithocolletinae) larvae in leaves using digitising techniques at visible and near-infrared light. - Antenna 26: 249-252.

Zemek R., Prenerová E. \& Weyda F. 2007a: The first record of entomopathogenic fungus Paecilomyces fumosoroseus (Deuteromycota: Hyphomycetes) on the hibernating pupae of Cameraria ohridella (Lepidoptera: Gracillariidae). - Entomol. Res. 37: 135-136.

Zemek R., Prenerová E., Volter L., Weyda F. \& Skuhravý V. 2007b: Perspectives for the biological control of Cameraria ohridella. — Comm. Appl. Biol. Sci. 72: 521-527.

Zemek R., Preneroví E., Awad M. \& Hussein H.M. 2012: Potential of the strain of entomopathogenic fungus Isaria fumosorosea CCM 8367 as a biological control agent against Cameraria ohridella and other pests. - Acta Fytotech. Zootech. 15: 79-80.

Žurovec M., Kodrík D., Yang C., Sehnal F. \& Scheller K. 1998: P25 component of Galleria silk. - Mol. Gen. Genet. 257: $264-270$.

Received August 7, 2014; revised and accepted September 22, 2014 Prepublished online October 20, 2014 